VARIA / VARIA

\section{EL HERBARIO DE VARIEDADES DE VID DE SIMÓN DE ROJAS CLEMENTE Y OTRAS APORTACIONES. VALOR CIENTÍFICO Y UTILIDAD SOCIOCULTURAL DE SU LEGADO}

\author{
María-Carmen Martínez \\ Consejo Superior de Investigaciones Científicas \\ ORCID iD: https://orcid.org/0000-0003-0653-8015 \\ carmenmartinez@mbg.csic.es \\ Pilar Gago \\ Consejo Superior de Investigaciones Científicas \\ ORCID iD: https://orcid.org/0000-0002-6170-9879 \\ pgago@mbg.csic.es \\ José-Luis Santiago \\ Consejo Superior de Investigaciones Científicas \\ ORCID iD: https://orcid.org/0000-0002-0656-5665 \\ santi@mbg.csic.es
}

Cómo citar este artículo/Citation: Martínez, M. C., Gago, P., Santiago, J. L., Boso, S. y Velayos, M. (2019). El herbario de variedades de vid de Simón de Rojas Clemente y otras aportaciones. Valor científico y utilidad sociocultural de su legado. Arbor, 195 (791): a494. https://doi.org/10.3989/arbor.2019.791n1007

Recibido: 29 noviembre 2017. Aceptado: 18 marzo 2018.

RESUMEN: Desde la antigüedad han destacado las aportaciones españolas al ámbito de la caracterización de las variedades de vid, sobresaliendo entre todas ellas, las realizadas por Simón de Rojas Clemente y Rubio en los inicios del siglo XIX, quien llegó al ámbito de la vid de una manera casual y gracias a una historia rocambolesca, digna de una novela de aventuras. Este autor está considerado como el creador de una disciplina científica, la ampelografía, que se ocupa de la caracterización de la vid (Vitis vinifera L.). Desarrolló el primer método científico de descripción de las vides, determinando los órganos de la planta que debían ser medidos y analizados, el momento del ciclo vegetativo en que debía tomarse cada dato en cada órgano, el modo de hacerlo o los detalles que debían ser estudiados en cada uno. Propuso incluso una terminología, hasta entonces inexistente, para referirse a cada una de las partes de las hojas de vid, las flores, los racimos, las bayas, las semillas o los sarmientos. Describió con precisión las variantes morfológicas, de tamaño, de color, de presencia o ausencia y tipo de pelos, etc., que pueden encontrarse en cada uno de los órganos de esta planta. El desarrollo de este método científico está basado en las variedades de vid recogidas y estudiadas por Clemente en Andalucía entre 1803 y 1804, cuyos resultados se publicaron en 1807 en su obra Ensayo sobre las variedades de vid que vegetan en Andalucía. En el Real Jardín Botánico de Madrid se conserva el material vegetal herborizado (hojas y pámpanos) de cada una de estas variedades estudiadas y cuyos resultados se incluyen en el citado libro. Este herbario, con 186 pliegos, puede ser considerado el más antiguo del mundo de variedades de vid cultivadas, con 214 años de antigüedad. Además de ser la base para la creación de la citada disciplina científica es reflejo de la diversidad existente a principios del siglo XIX en Andalucía en este cultivo. Es por todo ello un material de alto valor científico, museístico y sociocultural.

PALABRAS CLAVE: Simón de Rojas Clemente; herbarios; Vitis vinifera; ampelografía.
THE VINE VARIETY HERBARIUM AND OTHER CONTRIBUTIONS OF SIMÓN DE ROJAS CLEMENTE TO VITICULTURAL KNOWLEDGE: THE SCIENTIFIC VALUE AND SOCIOCULTURAL APPLICABILITY OF HIS LEGACY

Susana Boso

Consejo Superior de Investigaciones Científicas ORCID iD: https://orcid.org/0000-0003-3736-3991 susanab@mbg.csic.es

Mauricio Velayos

Consejo Superior de Investigaciones Científicas ORCID iD: https://orcid.org/0000-0002-0919-3545 velayos@rjb.csic.es

Copyright: (C) 2019 CSIC. Este es un artículo de acceso abierto distribuido bajo los términos de la licencia de uso y distribución Creative Commons Reconocimiento 4.0 Internacional (CC BY 4.0).

ABSTRACT: Spain has a long history of contributing towards the characterization of vine varieties. Of particular note, however, is the work of Simón de Rojas Clemente y Rubio, who in the 19th century entered the world of vines and viticulture unexpectedly, in a manner reminiscent of what might be read in an adventure novel. This author is deemed to be the father of ampelography, the discipline that focuses on the characterization of Vitis vinifera $L$. He developed the first scientific method for describing vines, indicating which organs of the plant should be measured and analysed, how and when in the life cycle this should be done, and the details that needed to be taken into account. He developed new terminology to refer to different parts of the leaf, flowers clusters, berries, seeds and canes, and described variations in morphology, size, colour, and the possession of hairs by the different organs, developing his methods through the examination of material he himself collected in Andalusia in 18031804. The results of this work were published in 1807 in his Ensayo sobre las variedades de vid que vegetan en Andalucía. The Royal Botanical Garden in Madrid conserves the material he herborised (leaves and shoots) for each of the varieties he studied. Now 214 years old, the 186 entries of this work constitute the oldest of all vine variety herbaria and provided the basis for the creation of ampelography as a scientific discipline. Today, this herbarium offers unparalleled insight into vine cultivation in early 19th century in Andalusia. It is without doubt an important museum piece of great scientific and sociocultural value.

KEYWORDS: Simón de Rojas Clemente; herbaria; Vitis vinifera; ampelography. 
TRADICIÓN ESPAÑOLA EN EL ESTUDIO DE VITIS VINIFERA L. LA LLEGADA DE SIMÓN DE ROJAS CLEMENTE AL CAMPO DE LA VID Y SUS APORTACIONES

Analizando la historia y evolución de los estudios sobre las variedades de vid y las aportaciones realizadas ya desde la época de los romanos por los habitantes de la Península Ibérica, nos damos cuenta del enorme valor que tienen no solo para España, el primer país en superficie vitícola del mundo, sino para el ámbito vitivinícola mundial.

El primero del que tenemos referencia fue Columela, nacido en Gades, en la Bética de la Hispania Romana, que en su obra Los doce libros de agricultura, escrita en torno al año 42 d. C., realiza una primera descripción de 58 variedades de vid, apuntado que "cada región y casi cada parte de región tiene sus especies particulares de vid a las cuales se les dan nombres consagrados por el hábito, que algunas variedades han cambiado de nombre al cambiar de lugar, y que, otras, al cambiar de lugar, han cambiado de calidad hasta el punto de no poder ser reconocidas" (Viala y Vermorel, 1910). Le sigue Abu Zacaria, andalusí, que vivió en Sevilla en el siglo XII y pertenecía a la escuela agronómica andalusí. En su Libro de agricultura, trata diversos aspectos relacionados con la viticultura, citando además los nombres de algunas variedades, de las que señala lo siguiente: "existían uvas de muchas especies: negras, redondas, largas y de una figura media, entre bermejas y amarillas, tempranas, tardías y ni tardías ni tempranas". Este libro fue traducido del árabe por Banqueri en 1802 y posteriormente publicado un "arreglo" realizado por Claudio Boutelou, a partir de la traducción de Banqueri (Abu Zacaria, 1878). Abu Zacaria aportó datos muy precisos sobre el cultivo de la vid en la Península Ibérica y sobre la importancia que había adquirido concretamente en el sur (Föex, 1891), citando nombres de variedades al azar, según su aspecto (Roy-Cheveir, 1900).

Ibn al-Baïthar, médico y botánico andalusí, nacido a finales del siglo XII en la provincia de Málaga, también realizó importantes aportaciones en el campo de la viticultura española, citando incluso, como señala Roy-Chevrier (1900), nombres de variedades todavía reconocidos hoy por los ampelógrafos españoles.

En el siglo XVI, Gabriel Alonso de Herrera, nacido en Talavera de la Reina (Toledo), aunque formado en Granada y habiendo completado sus estudios viajando por Europa, publica en 1513 su obra Agricultura general, en cuyo Libro segundo de los seis que componen la obra, trata sobre las viñas y sus particularidades dellas, y de los parrales, donde cita los nombres de 18 variedades de vid, incluyendo descripciones de muchas de ellas. EI
Cardenal Cisneros, a expensas propias, se ocupó de la difusión de esta obra que fue traducida a diversos idiomas y de la que se realizaron numerosísimas ediciones. En 1818, la Real Sociedad Económica Matritense patrocinó una nueva edición en la que se incluían diversas "adiciones" realizadas por distintos autores especializados en cada uno de los temas. Se ocupó de las "adiciones" del Libro segundo, que trata de la vid, Simón de Rojas Clemente, el protagonista del presente artículo.

En el siglo XVIII, Josep Antonio Valcárcel, ilustrado español de la Escuela de Levante y miembro de la Sociedad Económica de Amigos del País de Valencia, publica su obra Agricultura general, entre los años 1765 y 1799. Dicha obra consta de diez tomos, incluyendo en el tomo VIII, escrito en 1791, diversos temas relacionados con la vid y el vino, donde cita los nombres de más de veinte variedades, diferenciando además la Vitis vinifera cultivada de la Vitis silvestris o Labruscas, a las que denomina parrizas (Cabello et al., 2003).

Es a principios del siglo XIX cuando, debido a una historia digna de una novela de aventuras, entra en el campo de la viticultura Simón de Rojas Clemente y Rubio, nacido en Titaguas (Valencia) en 1777. De origen humilde, ingresó con diez años en el seminario y adquirió una amplia formación en distintas disciplinas relacionadas con las humanidades (filosofía, filología, griego, latín, hebreo...), aunque sentía una gran atracción por las ciencias naturales. Con veintitrés años, en 1800, se marchó a Madrid, donde estudió árabe, botánica, mineralogía, química y otras disciplinas. Allí sus gustos se decantaron por lo que entonces era la ciencia de moda, la botánica. Educado bajo la protección de un científico respetado en toda Europa, Antonio José Cavanilles, Simón de Rojas Clemente formaría, junto a los otros discípulos predilectos de Cavanilles (Mariano Lagasca y José Demetrio Rodríguez), la punta de lanza de la disciplina en España, la llamada Escuela de Cavanilles. Antonio José Cavanilles se había formado a su vez bajo la tutela de grandes botánicos franceses (André Thouin y Antoine Laurent de Jussieu), manteniendo a lo largo de su vida estrecha relación con los mejores científicos y botánicos internacionales de la época (Alexander von Humboldt, Aimé Bonpland, y Carl Ludwig Willdenow) (Martín Polo, 2016). A su llegada en 1801 al Real Jardín Botánico de Madrid (en lo sucesivo RJB), fue quien introdujo en España los procedimientos taxonómicos de Linneo, que estaban revolucionando los estudios de la botánica en el mundo. Mostraba a la vez Cavanilles un gran interés y preocupación por el aprovechamiento de los recursos naturales y su uso en la agricultura, en la agronomía y en otros campos, visión que sin duda transmitió a Clemente. 
En 1802, Simón de Rojas Clemente fue nombrado profesor de la cátedra de árabe de la Universidad de Madrid. Allí llegó como alumno Domingo Badía, que compartía con su profesor un gran interés por las ciencias naturales. Badía ya conocía el árabe por haber sido criado en Cuevas de Almanzora (Almería), donde había convivido con el ambiente morisco de la zona, y por haberlo perfeccionado en Córdoba. Según cuenta el propio Clemente (Martín Polo, 2016), Badía hizo grandes progresos rápidamente en el aprendizaje de dicha lengua, y al poco tiempo propuso a Clemente acompañarle en un viaje científico al interior de África, que Godoy, hombre fuerte del gobierno en aquella época, le había encargado realizar. Dicha misión, que en realidad había sido una propuesta de Badía, parece que fue aprobada por los dirigentes de la época, con la condición de que llevase un acompañante, pareciéndoles Clemente el más idóneo por sus conocimientos de árabe. La idea de este viaje bien remunerado atrajo enormemente a Clemente, que vería en ello una oportunidad única de ampliar sus conocimientos científicos y de conocer una parte del mundo prácticamente inexplorada para los occidentales. Aunque su maestro Cavanilles, sus amigos, e incluso su familia, insistían en que no participase en tal aventura, Badía acabó finalmente convenciéndole. El plan de Badía incluía disfrazarse de árabes durante un tiempo, utilizar documentación y nombres falsos (Ali-Bey Abdalak, Domingo Badía y Mohamad Ben-Alí, Simón de Rojas Clemente), y hasta someterse a una circuncisión, para hacerse pasar por auténticos musulmanes. Según Badía, esta era la única manera de llevar a buen término su expedición, debido a la poca o nula presencia de occidentales en África y al peligro que suponía para personas de otras religiones y culturas adentrarse en tierras musulmanas.

Los preparativos previos incluyeron viajes a Francia e Inglaterra, con el fin de intercambiar opiniones con determinadas personas y reunir el instrumental y material científico necesario, además de disfraces, regalos para el sultán y otros materiales. Según cuenta Clemente en sus cartas, durante su estancia en Londres Badía se sometió a la "inexcusable operación" (circuncisión), aprovechando un día que Clemente había salido a herborizar muestras en los bosques próximos a Londres. La operación le resultó a Badía tan cruel y penosa que le desaconsejó a Clemente someterse a ella (Martín Polo, 2016).

Regresaron después a España disfrazados ya de árabes, permaneciendo por un tiempo en Andalucía y haciendo creer a todo el mundo que lo eran. Aunque el plan inicial era que Clemente le acompañase, la realidad es que, aduciendo cuestiones de seguridad, Badía partió solo hacia África el 29 de junio de 1803, con la promesa de que llamaría a Clemente para que se incorporase más tarde. Poco tiempo después, Badía le mandaba una carta en la que, sin darle muchas explicaciones, le indicaba que no iba a ser posible su paso a África, cosa que efectivamente nunca hizo. Aunque se apunta que una de las razones para dejarlo en España fue la no circuncisión de Clemente, la conclusión a la que llega Martín Polo (2016) es que Clemente se quedó por decisión de los gobernantes del momento, que estimaron que ya no era necesaria su participación. La misión encomendada era en realidad de espionaje y tenía entre otros objetivos la preparación del terreno para la conquista de Marruecos y otras zonas de África, quedando muy poco espacio, o quizá ninguno, para cuestiones científicas.

Entre 1803 y 1807 Badía en solitario, bajo la identidad de Ali-Bey, lleva a cabo la misión, haciendo también grandes aportaciones, entre otras, a la cartografía de África. Tras la guerra de la independencia, y después de ser acusado de afrancesado, acaba en Francia, donde publica en 1814, como Ali-Bey, un libro de memorias contando sus aventuras africanas entre 1803 y 1807 (Escribano Martín, 2005). Dicha biografía fue traducida posteriormente al inglés y al alemán en 1816, al italiano entre 1816 y 1817 y muchos años más tarde, en 1836, al español. Es en esta edición española cuando se descubre al mundo que Ali-Bey era en realidad el español Badía (Escribano Martín, 2005), identidad que hasta entonces había permanecido oculta y que solo Simón de Rojas Clemente y pocos más conocían.

Todas estas circunstancias y algunas que relatamos a continuación explican, como veremos más adelante, muchas cuestiones relacionadas con los estudios de Clemente sobre la vid, con el herbario e incluso con la publicación de su obra.

La partida de Badía en solitario produjo una gran decepción en Clemente. Fue entonces cuando Godoy, para mantener su silencio con relación a la misión de Badía y su identidad en África (Ali-Bey), le encargó un estudio muy bien remunerado (1.500 reales mensuales) sobre la historia natural del Reino de Granada (Martín Polo, 2016), garantizándole que trabajaría con total independencia de cualquier autoridad. Hasta marzo de 1804 y con el objeto de proteger la identidad de Badía en África, Simón de Rojas Clemente siguió disfrazado de árabe, siendo conocido con el apodo del "moro sabio".

Esta rocambolesca historia fue la razón por la cual Clemente llegó el 26 de mayo de 1803 a Andalucía y acabó en el verano de ese mismo año en Sanlúcar de Barrameda (Cádiz), alojado en casa de Francisco Terán, 
bodeguero, propietario de viñas, y destacado miembro de la Sociedad de Amigos del País.

Se produjo a partir de este momento un giro decisivo en la trayectoria vital y científica de Simón de Rojas Clemente, quién sumó el estudio de la vid a sus otros trabajos (criptogamia, algas (Dosil Mancilla, 2007) y trigos españoles y europeos (Fernández Pérez y Gomis Blanco, 1990). Para el estudio de la vid contaba con el apoyo de una red de colaboradores constituida por la élite ilustrada de hacendados locales, abiertos todos ellos al progreso y deseosos de modernizar los modos de cultivo tradicionales.

El fallecimiento de Cavanilles en 1804 y su sustitución como director del RJB, primero por Francisco Zea y posteriormente por Claudio Boutelou, partidarios ambos de dar a la botánica un enfoque mucho más práctico (Martín Polo, 2016), produjo paralelamente un cambio importante en los estudios realizados a partir de entonces en esta institución. Con el nombramiento de Zea se emprendió un plan (en el que participó de forma muy activa Francisco Terán) de creación de 24 establecimientos en distintos puntos de España, cuyo objetivo era hacer llegar la botánica a la agricultura, contribuyendo así al desarrollo rural español. Aunque la mayoría de estos establecimientos no llegaron a ser realidad, sí se inició la creación del Jardín de Aclimatación de Sanlúcar de Barrameda (Andalucía), también llamado Jardín de la Paz en honor a Godoy.

Según Martín Polo (2016), el 31 de julio de 1804 (un año después de haberle hecho el encargo) Clemente ya había terminado la descripción de las variedades de vid recogidas en Andalucía y entregado la primera versión de su obra Ensayo sobre las variedades de vid común que vegetan en Andalucía, en donde incluía los resultados de dicho trabajo. Su publicación sin embargo fue retenida por Godoy, por miedo a descubrir la identidad de Ali-Bey y poner en peligro su vida y la misión de espionaje, hasta después de tener constancia de la salida del espía de África, cosa que ocurrió en octubre de 1805. Clemente aprovechó este tiempo de espera en Andalucía para perfeccionar su obra y completarla con nuevos estudios. El 23 de julio de 1805 fue nombrado bibliotecario del RJB, aunque pidió una prórroga para su incorporación hasta octubre de ese año, alegando que debía terminar los trabajos que estaba realizando en Andalucía. En los preparativos de su vuelta a Madrid, él mismo informaba de que había reunido más de 80 arrobas de muestras y material vegetal que debía trasladar a las instalaciones del RJB, donde se le había pedido que reuniese todo.
En julio de 1806 Godoy da el visto bueno para la impresión de la obra, que no verá la luz hasta finales de 1807, después de muchos recortes en el presupuesto, de muchas disputas sobre quién debería pagar el coste y de muchos cruces de cartas (Martín Polo, 2016). Clemente insistía en que el texto debería ser acompañado de láminas en color con dibujos descriptivos de, como mínimo, 12 variedades de las 119 que componían la obra. Señalaba también que los dibujos debían ser realizados a partir de modelos al natural, poniendo como fecha tope para su entrega finales de septiembre o principios de octubre de 1806, ya que debía ser editado en diciembre de ese mismo año. Para la realización de los dibujos de esas 12 variedades, Clemente dio indicaciones muy precisas de dónde podían ser encontrados los ejemplares vivos que servirían como modelos. Informaba que solo una de ellas se cultivaba en el RJB y que podría ser dibujada por los profesores de este centro. Dos eran muy comunes en Granada y podrían ser dibujadas por los miembros de la Sociedad Económica de Granada y nueve se cultivaban en el Jardín de Aclimatación de Sanlúcar, por lo que la realización de las láminas podría correr a cargo de la Sociedad Económica de Sanlúcar. Añadía Clemente en sus indicaciones que había 23 variedades más en el Jardín de Aclimatación de Sanlúcar, cuyos dibujos deberían realizarse debido al alto interés económico de estas variedades, añadiendo que si, debido al coste que suponía, no se podían incluir en esta primera edición, podían quedar ya realizados para ediciones futuras o para consulta en el RJB. La primera edición publicada no llevó láminas de ninguna variedad porque nadie quería hacerse cargo del pago a los ilustradores y porque encarecía la edición. Según Martín Polo (2016), parece que finalmente y después de muchas promesas incumplidas de unos y otros, la imprenta acabó reclamándole a Clemente los gastos de esta primera edición, teniendo que pagar parte o la totalidad de su publicación de su escaso salario.

Tan importante y magnífico fue su trabajo que la primera edición de su libro se tradujo al alemán y al francés en vida de Clemente, siendo el propio rey de Francia, Luis XVIII, quién mandó que se repartiesen ejemplares entre las autoridades civiles y departamentales del país. En años posteriores investigadores de numerosos países imitaron sus pasos publicando obras de ampelografía en las que describían sus variedades siguiendo la metodología de Clemente, destacando entre todas ellas la de Viala y Vermorel (1910), quienes describen en siete grandes tomos numerosas variedades de vid de diferentes países, haciendo múltiples referencias a Clemente y a su obra. 
Con relación a las láminas con las que quería ilustrar la primera edición de su obra, parece que algunas de ellas llegaron a realizarse, aunque se cree que estas primeras desaparecieron (Martín Polo, 2016). En la edición ilustrada de 1879 , mucho después del fallecimiento de Clemente (1827), se incluyeron las láminas de las variedades que él había indicado en su primer listado e incluso alguna más. Según parece, estas láminas se realizaron de nuevo para esta edición. Esto nos lleva a pensar que Clemente pudo haber llevado consigo estaquillas procedentes de las plantas del Jardín de Aclimatación de Sanlúcar para plantar una réplica de todas ellas en el RJB, y que fueron estas últimas cepas las que se utilizaron posteriormente como modelo al natural para realizar las láminas de la edición ilustrada de 1879. Se recuerda que, por un lado, según las indicaciones que daba Clemente para realizar las láminas en la primera edición, en el RJB solo había una variedad de la lista que él había elaborado para que fuesen dibujadas y que en su traslado desde Sanlúcar a Madrid llevaba más de 80 arrobas de muestras y material vegetal. Por otro lado, como se verá más adelante, el 27 de marzo de 1808 las masas enfurecidas contra los afrancesados, entraron en el Jardín de Aclimatación de Sanlúcar destrozándolo por completo, con lo cual es imposible que los ilustradores de la edición de 1879 utilizasen como modelo las que crecían en Sanlúcar. Una segunda hipótesis es que, tal y como aconsejaba Clemente, las láminas hubiesen sido realizadas todas en la época de la primera edición, aunque no incluidas en ella por falta de fondos, y que quedasen inéditas hasta la segunda edición, descartándose así la teoría de que se han perdido o han desaparecido.

\section{EL VALOR DEL HERBARIO DE VIDES DE CLEMENTE CONSERVADO EN EL REAL JARDÍN BOTÁNICO DE MADRID. INTERÉS CIENTÍFICO, MUSEÍSTICO Y ENO- TURÍSTICO}

El herbario del RJB, propiedad del Consejo Superior de Investigaciones Científicas (CSIC) y patrimonio del estado español, es una colección pública de uso restringido y compuesta por más de un millón de ejemplares organizados de acuerdo a sistemas estandarizados de clasificación. En él se encuentran representados todos los grupos de plantas, con una gran presencia de ejemplares de la Península Ibérica, así como de plantas de Iberoamérica. Entre estas últimas destacan algunas colecciones únicas, fruto de las primeras expediciones científicas al nuevo mundo (http://www.rjb.csic.es/jardinbotanico/), de incalculable valor histórico y científico. No menos importante que todas ellas es la colección herborizada de variedades de vid realizada por Simón de Rojas Clemente y Rubio entre 1803 y 1804 en Andalucía, que nunca hasta ahora había sido objeto de estudio.

El herbario de vides de Clemente era bien conocido por taxónomos y botánicos en general pero nunca había sido estudiado por científicos especializados en la vid, combinando en un mismo trabajo los conocimientos sobre ampelografía y sobre la obra de Clemente.

En su correspondencia personal, conservada en el RJB, queda constancia de los recorridos que hacía y de lo mucho que gozaba con el trabajo que estaba Ilevando a cabo. El 5 de julio de 1803 Clemente escribió a su padre desde Cádiz haciéndole saber que había estado doce días de viaje por El Puerto de Santa María, Rota, Jerez y Sanlúcar, y que en esa última población había pasado ocho días en "casa de un labrador riquísimo que habita en un palacio y tiene las mejores bodegas del mundo", la "mansión querida" a la que hace referencia, y que es, como ya se mencionó anteriormente, la casa del bodeguero y propietario de viñas Francisco Terán. El 24 de septiembre de 1803 escribió nuevamente para contar que había abandonado Cádiz y que se encontraba felizmente instalado en Sanlúcar, "corriendo pueblos y viñas y recibiendo mil atenciones [...]".

Aunque el centro de operaciones de Clemente estaba en Sanlúcar, pronto el trabajo de recolección se extendió a Arcos, Trebujena, Espera, Rota, Chipiona, Chiclana, Conil, Tarifa, Algeciras y otros lugares. Esta recolección se llevó a cabo con la ayuda de una importante red de informantes en Sanlúcar y en la provincia gaditana, a los que llama "los Plinios y los Columelas del campo", que le "comunicaron muy generosamente sus preciosos conocimientos prácticos".

Lo que iba a ser una investigación limitada a la zona de Sanlúcar acabó por extenderse a gran parte de Andalucía (véase figura 1), gracias al encargo de Godoy de realizar una historia natural del Reino de Granada para "entretener" a Clemente hasta que Badía finalizase su labor de espionaje en África y consiguiese salir sin ser descubierto. El viaje científico que emprendió por tierras de Granada durante el año 1804 le permitió ampliar su herbario y el número de variedades que finalmente incluiría en el ensayo, a cuya publicación Godoy dio luz verde en 1806 pero que, como hemos indicado en el apartado anterior, no se publicó hasta finales de 1807.

Según los datos que se han podido recabar y la observación directa de los pliegos, el herbario de vides 
Figura 1. Localidades citadas por Simón de Rojas Clemente como visitadas por él mismo en la provincia de Cádiz

Localidades más citadas en el Ensayo sobre las variedades de la vid común que vegetan en Andalucía

Fuente: elaboración propia.

de Clemente es el más antiguo del mundo, con 214 años de antigüedad. El siguiente herbario de vides más antiguo sería el conservado en Vassal (Francia), que data de los años 1870-1880, con 147 años de antigüedad (Boursiquot, comunicación personal).

En la tabla 1 figuran los nombres de los ejemplares conservados en los pliegos del herbario, que ascienden a un total de 186, cuyos lugares de procedencia son los siguientes: Sanlúcar (128 pliegos), Paxarete
Localidades citadas en la introducción por Clemente como visitadas por él mismo en la provincia de Cádiz

Base de operaciones de Clemente

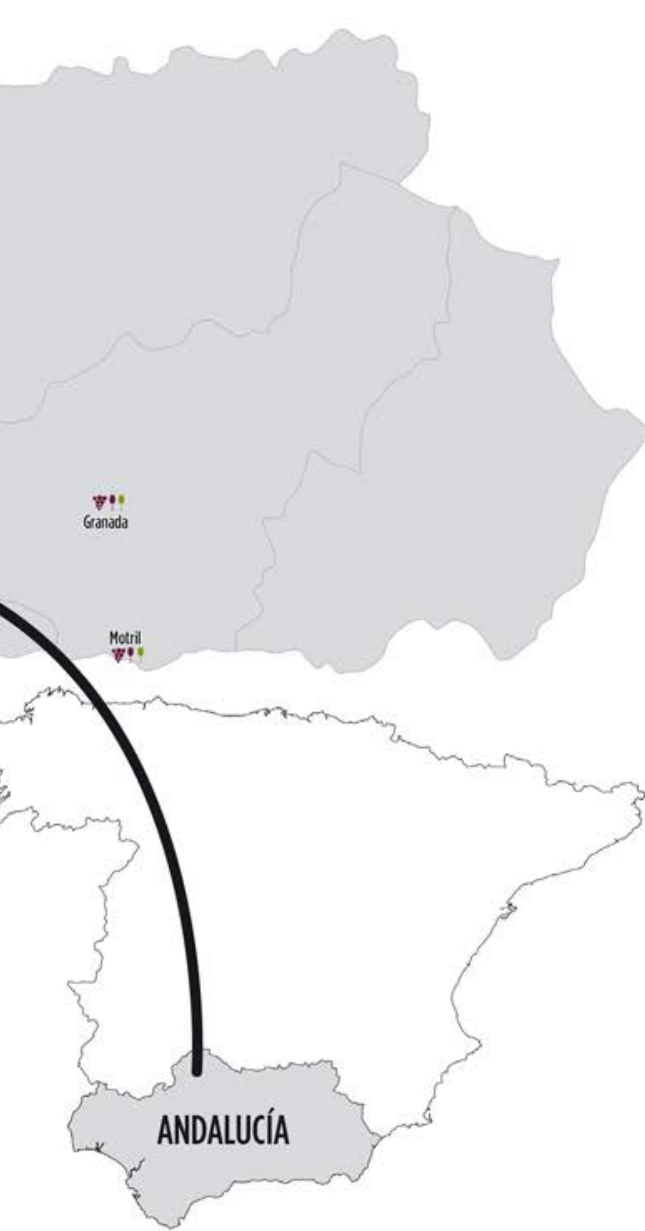

(13), Jerez (7), Pajarete (5), Xerez (5), Bornos (4) y Trebujena (1). Para los 23 pliegos restantes no hay información sobre el lugar de procedencia. En el libro de Clemente se incluye la descripción de 119 variedades; de ellas hay 24 variedades descritas que no tienen su pliego correspondiente en el herbario del RJB (véase tabla 2) y 15 de las que existe pliego, ya incluidas en la tabla 1 , pero que no aparecen descritas en el texto del libro de Clemente. 
Tabla 1. Nombres de las accesiones en los pliegos del herbario de Clemente conservado en el Real Jardín Botánico de Madrid

\begin{tabular}{|c|c|c|c|c|c|c|c|}
\hline $\begin{array}{l}\text { № } \\
\text { herbario }\end{array}$ & $\begin{array}{l}\text { № libro } \\
\text { Clemente }\end{array}$ & Nombre común & Nombre culto & $\begin{array}{l}\text { № } \\
\text { herbario }\end{array}$ & $\begin{array}{l}\text { № libro } \\
\text { Clemente }\end{array}$ & Nombre común & Nombre culto \\
\hline 709375 & & - & - & 709967 & 51 & Cepa canasta & prolifera Prolifera \\
\hline 709626 & 74 & Agracera & $\begin{array}{l}\text { florentissima } \\
\text { florentissima }\end{array}$ & 709964 & 54 & Cienfuentes & $\begin{array}{l}\text { subcompressa } \\
\text { Subcompressa }\end{array}$ \\
\hline 709848 & 74 & Agracera & $\begin{array}{l}\text { florentissima } \\
\text { Floribunda }\end{array}$ & 709696 & 4 & Colgadera & ligeri Degenerans \\
\hline 709369 & 23 & Albillo castellano & $\begin{array}{l}\text { racemosissima } \\
\text { racemosissima }\end{array}$ & 709707 & 14 & Cordovi & pellucida \\
\hline 709714 & 23 & Albillo castellano & racemosissima & 709363 & 14 & Cordoví & pellucida pellucida \\
\hline 709586 & 28 & Albillo de Huelba & fecunda herrerae & 709706 & 14B & Cordovi petiolis pilosis & pellucida \\
\hline 709983 & 28 & Albillo de Huelba & herrerae Fecunda & 709598 & 26 & De Beguillet & intermedia beguilleti \\
\hline 709378 & 29 & Albillo loco & valida valida & 709717 & 26 & De Beguillet & beguilleti Intermedia \\
\hline 709984 & 29 & Albillo loco & valida Valida & 709855 & 70 & De Bidet & bidedi Subdulcis \\
\hline 709715 & 24 & Albillo negro & succosa & 709614 & 105 & De Boutelou & decipiens bouteloui \\
\hline 709383 & 27 & Albillo pardo & subaurata heppe & 709831 & 105 & De Boutelou & bouteloui Decipiens \\
\hline 709718 & 27 & Albillo pardo & heppe Subaurata & 709968 & 50 & De Columela & columellae Ferax \\
\hline 709348 & 98 & Almuñécar & longa longa & 709697 & 5 & De Fuentedueña & $\begin{array}{l}\text { fuenteduennae } \\
\text { Affinis }\end{array}$ \\
\hline 709361 & 92 & Arrobal & ovata ovata & 709602 & 25 & de Laleña & aberrans lalennae \\
\hline 709823 & 92 & Arrobal & ovata Ovata & 709716 & 25 & De Laleña & Ialennae Aberrans \\
\hline 709954 & 66 & Bernala & bernala Glabriuscula & 709618 & 97 & De Loxa & eximia eximia \\
\hline 709970 & 45 & Beva & bullata Bullata & 709837 & & De parra & Autumnalis \\
\hline 709610 & 45 & Beva & bullata bullata & 709392 & 72 & De Soto & soti soti \\
\hline 709951 & 71 & Blanquecina & albicans Albicans & 709850 & 72 & De Soto & soti Soti \\
\hline 709606 & 71 & Blanquecina & albicans albicans & 709840 & 77 & Ferrar blanco & speciosa Speciosa \\
\hline 709949 & 99 & Botón de gallo & orchidea Orchidea & 709846 & 76 & Ferrar común & $\begin{array}{l}\text { autumnalis } \\
\text { Autumnalis }\end{array}$ \\
\hline 709360 & 99 & Botón de gallo & orchidea orchidea & 709950 & 76 & Ferrar común & autumnalis Fenera \\
\hline 709838 & 100 & $\begin{array}{l}\text { Botón de gallo } \\
\text { negro }\end{array}$ & jucunda Jucunda & 709608 & 76 & Ferrar común & $\begin{array}{l}\text { autumnalis } \\
\text { autumnalis }\end{array}$ \\
\hline 709600 & 100 & $\begin{array}{l}\text { Botón de gallo } \\
\text { negro }\end{array}$ & jucunda jucunda & 709965 & 53 & Fray gusano de Maina & $\begin{array}{l}\text { rotundifolia } \\
\text { Rotundifolia }\end{array}$ \\
\hline 709390 & 87 & Cabriel & rubra rubra & 709708 & 15 & $\begin{array}{l}\text { Fray gusano de } \\
\text { Miraflores }\end{array}$ & merleti Viridis \\
\hline 709843 & 87 & Cabriel & rubra Rubra & 709374 & 15 & $\begin{array}{l}\text { Fray gusano de } \\
\text { Miraflores }\end{array}$ & viridis merleti \\
\hline 709966 & 52 & Calona & colonia Erectiuscula & 709969 & 46 & Galana & galana Galana \\
\hline 709619 & 79 & Calona negra & exquisita exquisita & 709589 & 46 & Galana & galana galana \\
\hline 709842 & 79 & Calona negra & exquisita Exquisita & 709607 & 35 & Gallega & anomala anomala \\
\hline 709827 & 115 & Cañocazo & hirsuta Sericea & 709977 & 35 & Gallega & $\begin{array}{l}\text { anomala Anomala } \\
\text { (con zarcillos entre } \\
\text { los nudos) }\end{array}$ \\
\hline
\end{tabular}




\begin{tabular}{|c|c|c|c|c|c|c|c|}
\hline $\begin{array}{l}\text { № } \\
\text { herbario }\end{array}$ & $\begin{array}{l}\text { № libro } \\
\text { Clemente }\end{array}$ & Nombre común & Nombre culto & $\begin{array}{l}\text { № } \\
\text { herbario }\end{array}$ & $\begin{array}{l}\text { № libro } \\
\text { Clemente }\end{array}$ & Nombre común & Nombre culto \\
\hline 709851 & 86 & Casco de tinaja & macrobotrys & 709615 & 42 & Garabatona & $\begin{array}{l}\text { diversifolia } \\
\text { diversifolia }\end{array}$ \\
\hline 709972 & 42 & Garabatona & $\begin{array}{l}\text { diversifolia } \\
\text { Diversofolia } \\
\text { espontanea con fruto }\end{array}$ & 709612 & 13 & Mantúo laeren & $\begin{array}{l}\text { conferta } \\
\text { confertissima }\end{array}$ \\
\hline 709973 & 42 & Garabatona & $\begin{array}{l}\text { diversifolia } \\
\text { Diversifolia }\end{array}$ & 709705 & 13 & Mantúo laeren & $\begin{array}{l}\text { confertissima } \\
\text { Conferta }\end{array}$ \\
\hline 709962 & 58 & Heben & fragilis Fragilis & 709703 & 11 & Mantúo morado & rubella \\
\hline 709711 & 19 & Jaén blanco & varronis Alba & 709350 & 84 & Martinecia & martinecii martinecii \\
\hline 709605 & 19 & Jaén blanco & alba varronis & 709853 & 84 & Martinecia & martinecii Martinezii \\
\hline 709613 & 18 & $\begin{array}{l}\text { Jaén negro de } \\
\text { Granada }\end{array}$ & crescencii crescencii & 709585 & 73 & Melonera & floribunda vittata \\
\hline 709611 & 17 & $\begin{array}{l}\text { Jaén negro de } \\
\text { Sevilla }\end{array}$ & coloratus stephani & 709852 & 73 & Melonera & vittata Fasciata \\
\hline 709710 & 17 & $\begin{array}{l}\text { Jaén negro de } \\
\text { Sevilla }\end{array}$ & stephani Colorata & 709976 & 36 & Mollar de Cádiz & $\begin{array}{l}\text { mollissima } \\
\text { Mollissima }\end{array}$ \\
\hline 709856 & 107 & Jamí & vivax & 709353 & 36 & Mollar de Cádiz & $\begin{array}{l}\text { mollissima } \\
\text { mollissima }\end{array}$ \\
\hline 709845 & & Jardona ???? & - & 709947 & 114 & Mollar de Granada & zeae \\
\hline 709593 & 88 & Jetubí bueno & grandis pliniana & 709712 & 20 & Mollar negro & mollis Mollis Clem. \\
\hline 709826 & 88 & Jetubí bueno & pliniana Grandis & 709713 & 20 & Mollar negro & $\begin{array}{l}\text { mollis Mollis Clem. } \\
\text { Obs. 2a }\end{array}$ \\
\hline 709370 & 78 & Jetubí loco & rara jonesia & 709351 & 20 & Mollar negro & mollis \\
\hline 709839 & 78 & Jetubí loco & jonesia Rara & 709357 & 91 & Moravita & nigrescens garideli \\
\hline 709356 & 75 & Langleya & nigerrima langleya & 709825 & 91 & Moravita Clemente & garideli Nigrescens \\
\hline 709849 & 75 & Langleya & langleya Nigerrima & 709979 & & $\begin{array}{l}\text { Moscatel de Málaga, } \\
\text { Listán?? }\end{array}$ & - \\
\hline 709841 & 82 & Leonada & sulcata Sulcata & 709834 & $104 ?$ & Moscatel gordo blanco & isidori Fumosa \\
\hline 709693 & 1 & Listan común & uberrima & 709359 & 103 & $\begin{array}{l}\text { Moscatel gordo } \\
\text { morado }\end{array}$ & obovata obovata \\
\hline 709963 & 57 & $\begin{array}{l}\text { Listan de } \\
\text { Paxarete }\end{array}$ & $\begin{array}{l}\text { pauperrima } \\
\text { Pauperrima }\end{array}$ & 709833 & 103 & $\begin{array}{l}\text { Moscatel gordo } \\
\text { morado }\end{array}$ & obovata Obovata \\
\hline 709605 & 3 & Listan ladrenado & antillana Atrovirens & 709590 & 101 & $\begin{array}{l}\text { Moscatel menudo } \\
\text { blanco }\end{array}$ & generosa generosa \\
\hline 709694 & 2 & Listan morado & hyacinthina & 709835 & 101 & $\begin{array}{l}\text { Moscatel menudo } \\
\text { blanco }\end{array}$ & generosa Generosa \\
\hline 709601 & 34 & Llorona & lacrymosa lacrymosa & 709354 & 102 & $\begin{array}{l}\text { Moscatel menudo } \\
\text { morado }\end{array}$ & moschata moschata \\
\hline 709975 & 37 & Malvasía & dulcissima Dulcissima & 709836 & 102 & $\begin{array}{l}\text { Moscatel menudo } \\
\text { morado }\end{array}$ & moschata Mostacha \\
\hline 709616 & 37 & Malvasía & dulcissima dulcissima & 709980 & & Moscatel. Listán?? & - \\
\hline 709384 & 10 & Mantúo bravío & silvatica sylvatica & 709588 & 104 & Moscatelón & fumosa isidori \\
\hline 709702 & $10 \mathrm{~B}$ & $\begin{array}{l}\text { Mantúo bravío } \\
\text { con flor }\end{array}$ & silvatica & 709373 & 8 & Palomino bravío & $\begin{array}{l}\text { venatorum } \\
\text { venatorum }\end{array}$ \\
\hline 709701 & 10 & $\begin{array}{l}\text { Mantúo bravío } \\
\text { Espontanea }\end{array}$ & silvatica & 709700 & 8 & Palomino bravío & venatorum \\
\hline 709620 & 9 & $\begin{array}{l}\text { Mantúo } \\
\text { castellano }\end{array}$ & fallax falax & 709699 & 7 & Palomino común & fissilis \\
\hline 709692 & 9 & $\begin{array}{l}\text { Mantúo } \\
\text { castellano }\end{array}$ & fallax & 709624 & 7 & Palomino común & fissilis fissilis \\
\hline 709365 & 12 & Mantúo de pilas & pensilis pensilis & 709625 & 63 & Perruno común & flava flava \\
\hline
\end{tabular}




\begin{tabular}{|c|c|c|c|c|c|c|c|}
\hline $\begin{array}{l}\text { № } \\
\text { herbario }\end{array}$ & $\begin{array}{l}\text { № libro } \\
\text { Clemente }\end{array}$ & Nombre común & Nombre culto & $\begin{array}{l}\text { № } \\
\text { herbario }\end{array}$ & $\begin{array}{l}\text { № libro } \\
\text { Clemente }\end{array}$ & Nombre común & Nombre culto \\
\hline 709704 & 12 & Mantúo de pilas & pensilis & 709956 & 63 & Perruno común & flava Flava \\
\hline 709953 & 67 & Perruno duro & firmissima Firmissima & 709349 & & var.macrophylla & macrophylla \\
\hline 709623 & 67 & Perruno duro & firmissima firmissima & 709352 & & var.mollis & mollis \\
\hline 709622 & 64 & Perruno negro & fertilis rocierii & 709362 & & var.pauperrima & pauperrima \\
\hline 709591 & 65 & Quintiniea & $\begin{array}{l}\text { glabriuscula } \\
\text { quintiniea }\end{array}$ & 709364 & & var.pellucida & $\begin{array}{l}\text { pellucida petislis } \\
\text { pilosis }\end{array}$ \\
\hline 709955 & 65 & Quintiniea & quintiniea Fertilis & 709367 & & var.prolifera & prolifera \\
\hline 709961 & 59 & Rabo de baca & $\begin{array}{l}\text { macrophylla } \\
\text { Macrophylla }\end{array}$ & 709372 & & var.rotundifolia & rotundifolia \\
\hline 709960 & 60 & Rebazo & $\begin{array}{l}\text { ignobilis Ignobilis } \\
\text { foliis subpilosis }\end{array}$ & 709389 & & var.rubella & rubella \\
\hline 709959 & 60 & Rebazo & $\begin{array}{l}\text { ignobilis Ignobilis } \\
\text { foliis subpilosis }\end{array}$ & 709391 & 113 & var.ruizia & ruizia \\
\hline 709830 & 113 & Ruizia & ruizia Ruizia & 709381 & & var.sinuosa & sinuosa \\
\hline 709366 & 90 & $\begin{array}{l}\text { Santa Paula de } \\
\text { Xerez }\end{array}$ & $\begin{array}{l}\text { praegrandis } \\
\text { praegrandis }\end{array}$ & 709386 & & var.speciosa & speciosa \\
\hline 709824 & 90 & $\begin{array}{l}\text { Santa Paula de } \\
\text { Xerez }\end{array}$ & $\begin{array}{l}\text { praegrandis } \\
\text { Pregrandis }\end{array}$ & 709388 & & var.subacida & subacida \\
\hline 709698 & 6 & Tempranillo & cupani Multiloba & 709380 & & var.subcompressa & subcompressa \\
\hline 709355 & 6 & Tempranillo & multiloba cupani & 709387 & & var.subdulcis & subdulcis \\
\hline 709376 & 108 & Terana & terana terana & 709382 & & var.sulcata & sulcata \\
\hline 709832 & 108 & Terana & terana Terana & 709385 & & var.tenera & tenera \\
\hline 709592 & 96 & $\begin{array}{l}\text { Teta de vaca } \\
\text { blanca }\end{array}$ & gracilis gracilis & 709982 & 31 & Verdagüilla & acerba Acerba \\
\hline 709948 & 96 & $\begin{array}{l}\text { Teta de vaca } \\
\text { blanca }\end{array}$ & gracilis Gracilis & 709603 & 31 & Verdagüilla & acerba acerba \\
\hline 709377 & 39 & Tintilla & turgens liebaulti & 709368 & 68 & Vigiriega común & prostrata prostrata \\
\hline 709974 & 39 & Tintilla & liebaulti Fingens & 709844 & 68 & Vigiriega común & prostrata Prostrata \\
\hline 709599 & 16 & Torrontés & issophylla isophylla & 709854 & 106 & Vigiriega de Motril & sachsi \\
\hline 709709 & 16 & Torrontés & issophylla & 709604 & 69 & Vigiriega negra & acidula catonis \\
\hline 709371 & 116 & Uva de rey & regalis regalis & 709952 & 69 & Vigiriega negra & catonis Acidula \\
\hline 709828 & 116 & Uva de rey & regalis Regalis & 709971 & 44 & Virgiliana & virgiliana Varians \\
\hline 709358 & 112 & Vaoa & nigricans vaoa & 709379 & 44 & Virgiliana & varians virgiliana \\
\hline 709829 & 112 & Vaoa & vaoa Nigricans & 709981 & & $\begin{array}{l}\text { Vitis racimosa. Listán } \\
\text { común }\end{array}$ & - \\
\hline 709609 & & var.autumnalis & autumnalis & 709594 & 62 & Ximenez & ximenecia ximenecia \\
\hline 709617 & & var.erectiuscula & erectiuscula & 709957 & 62 & Ximenez & ximenecia Ximenezia \\
\hline 709621 & & var.ferax & ferax & 709597 & 61 & Ximenez loco & indecora forsythia \\
\hline 709587 & & var.fragilis & fragilis & 709958 & 61 & Ximenez loco & forsythia Indecora \\
\hline 709595 & & var.ignobilis & ignobilis & 709978 & & Zedotí & - \\
\hline 709596 & & var.ignobilis & ignobilis & 709847 & 80 & $\begin{array}{l}\text { Zucarí. [№ } 117 \text { Ciuti; } \\
\text { Palladii??] }\end{array}$ & saccharata \\
\hline
\end{tabular}

El símbolo "?" indica que el correspondiente término no es completamente legible en las notas manuscritas presentes en el pliego.

Fuente: elaboración propia. 
Tabla 2. Variedades incluidas en el ensayo de Clemente que no tienen pliego en el herbario.

\begin{tabular}{|l|l|l|}
\hline $\begin{array}{l}\text { No libro } \\
\text { clemente }\end{array}$ & Nombre común & Nombre culto \\
\hline 21 & Mollar cano & versicolor \\
\hline 22 & Mollar negro bravío & duhamelii \\
\hline 30 & Albillo de Granada & leinweberi \\
\hline 32 & Verdal & milleri \\
\hline 33 & Abejera & impatiens \\
\hline 40 & Tinto & maculata \\
\hline 41 & Tomé & bretonneria \\
\hline 43 & Morrastell & valcarcelia \\
\hline 47 & Montúo castellano & dussieux \\
\hline 48 & Pecho de perdiz & picta \\
\hline 49 & Zurumí & bipartita \\
\hline 55 & Doradillo & aurantia \\
\hline 56 & Montúo perruno & canina \\
\hline 83 & Corazón de cabrito & exsucca \\
\hline 85 & Santa Paula de & longissima \\
\hline 89 & Granada & praedura \\
\hline 93 & de Ragol & dactilus \\
\hline 95 & Teta de negra & teretiuscula \\
\hline 109 & Albán real & sphaerocarpa \\
\hline 110 & Moscatel de Flandes & pseudoapiana \\
\hline 111 & Santa Isabel & elisabeth \\
\hline 117 & Cuití & palladii \\
\hline 118 & Casta de Ohanez & cacci \\
\hline 119 & Nievasea & nievasea \\
\hline
\end{tabular}

Fuente: elaboración propia.

Después de la observación de diferentes aspectos del material herborizado en los 186 pliegos (el aspecto de las hojas, grosor de los tallos de los pámpanos y algunos otros detalles), se concluye que gran parte de los pliegos, si no todos, contienen material procedente de plantas jóvenes. Si las hojas y los brotes procedieran de cepas/plantas adultas (se supone que las cepas originales lo serían), los tallos de los pámpanos deberían ser más gruesos y las hojas más grandes. Además, si se tratase de cepas adultas, los lugares de recogida de las muestras deberían ser los distintos puntos recorridos por Clemente o bien los lugares desde los que los viticultores le traían las muestras, y no Sanlúcar, tal y como se indica para la gran mayoría de los pliegos (128). La hipótesis que se plantea para explicar las características del material herborizado es que este material hubiera sido recogido a partir de plantas jóvenes. Así, después de realizar una primera localización, recolección y descripción del material en el verano de 1803, Clemente posiblemente recogió estaquillas de las plantas originales durante el invierno de 1803-1804, enraizándolas y plantándolas a continuación (en esa época no se injertaban) en una de las parcelas de lo que luego sería el Jardín de Aclimatación de Sanlúcar, para ir conservando en colección réplicas de todo lo que iba encontrando. En la primavera-verano de 1804 estas plantas darían sus primeros brotes y hojas, que aprovecharía Clemente para recoger y herborizar. No olvidemos que el objetivo de este jardín no era otro que el de reunir la mayor cantidad posible de plantas de interés agrario, con el fin de poder realizar diferentes actividades didácticas dirigidas a los agricultores, contribuyendo así al desarrollo de una agricultura moderna y al aprovechamiento de los recursos disponibles. Si como se plantea, Clemente hubiese enraizado y plantado réplicas de todas ellas en el invierno de 1803-1804, tres años más tarde, en septiembre de 1806, estas plantas podían estar ya dando racimos. Tal y como cuenta Martín Polo (2016) y se ha referido en el apartado anterior, con motivo de la primera edición de su libro, Clemente señala que los ilustradores de la Sociedad Económica de Sanlúcar podrían realizar dibujos al natural de una treintena de variedades de vid que se cultivaban en aquellas instalaciones. Para que estas plantas se encontrasen en esa época fructificando, tendrían que haber sido plantadas varios años antes, ya que la vid tarda en dar frutos un mínimo de tres años.

Aunque oficialmente el Jardín de Aclimatación de Sanlúcar se creó el 3 de mayo de 1806 y se nombró a Clemente director científico del mismo el 10 de julio de 1807, incorporándose a su nuevo puesto en octubre de ese mismo año, la colección de variedades tenía que llevar ya años plantada y estar en plena fructificación. Esta es la única manera de que él pudiese utilizarla con fines didácticos y divulgativos, tal y como relataba que hacía en las cartas dirigidas a sus amigos y familia (Martín Polo, 2016). En ellas les contaba también que estaba ampliando las colecciones con la introducción de nuevas plantas, entre ellas la vid, pero esto no es en absoluto incompatible con la existencia anterior en la colección de muchas de ellas. 
Se supone que fue en el período comprendido entre 1807 y el episodio de destrucción del Jardín de Aclimatación de Sanlúcar, en marzo de 1808, cuando Clemente habría recogido estaquillas de las diferentes variedades de vid por él estudiadas, al menos de las que él consideraba más importantes y de las que aconsejaba realizar láminas de dibujos, para plantar una réplica de cada una de ellas en el RJB. Recordemos una vez más que a finales de 1806, según señala Clemente, en el RJB solo había una variedad de vid de las que él tenía en su lista para ser dibujadas. Si tal y como indica Martín Polo (2016), las láminas para la edición ilustrada de 1879 (véase tabla 3), muchos años más tarde de la muerte de Clemente se realizaron de nuevo, en algún lugar tenían que estar las cepas dando frutos para que los ilustradores pudiesen utilizarlas como modelos y realizar los dibujos de los racimos que todos podemos contemplar en su obra (Rojas Clemente y Rubio, 1879). Otra opción, como ya se citó anteriormente, es que los dibujos que aparecen en esta edición ilustrada se hubiesen realizado para la primera edición, tal y como aconsejaba Clemente que se hiciese, aunque no pudieran ser incluidos en ella por falta de presupuesto, y que permaneciesen inéditos hasta entonces. Otra tercera posibilidad es que los dibujos de la edición ilustrada fuesen una copia de aquellos primeros.

El valor del herbario de Clemente no solo radica en su antigüedad y en su buen estado de conservación (véase figura 2), sino también en que su estudio nos permite conocer las variedades de vid existentes hace 214 años en Andalucía. Al tratarse de las muestras más antiguas de las que se dispone, se podrían sacar conclusiones sobre el origen de algunas de ellas, la antigüedad de su cultivo en España, su posible evolución, su relación con las variedades de vid cultivadas actualmente, e incluso con los ejemplares de vid silvestre que todavía hoy se encuentran en algunos bosques de Andalucía y que están siendo estudiados por algunos grupos de investigación (Ocete Rubio et al., 2007; Andrés et al., 2012).

La comparación entre las variedades existentes en aquella época y las actuales permite además analizar en profundidad y con datos concretos la influencia que tuvo la llegada a Andalucía, y por extensión a Europa, cien años más tarde, de plagas y enfermedades de la vid que en aquella época ni se conocían y que cambiaron por completo la viticultura a nivel mundial, como el oídio, la filoxera, el mildiu, o el black-rot. La comparación de las variedades recogidas por Clemente 75 años antes de la llegada de las citadas enfermedades a España (Johnson, 1990) con las que existen actualmente permitirá comprobar hasta qué punto se perdió diversidad vitícola.
Tabla 3. Lista de láminas incluidas en la edición ilustrada del ensayo de Clemente (1879).

\begin{tabular}{|c|c|c|}
\hline $\begin{array}{l}\text { № } \\
\text { Lámina }\end{array}$ & Nombre variedad & $\begin{array}{l}\text { Página de la } \\
\text { descripción }\end{array}$ \\
\hline I & Listán común & 41 \\
\hline II & Mantúo castellano & 44 \\
\hline III & Mantúo de Pilas & 45 \\
\hline IV & Jaen blanco & 46 \\
\hline V & Mollar negro & 47 \\
\hline VI & Albillo castellano & 48 \\
\hline VII & Albillo de Granada & 49 \\
\hline VIII & Ximénez Zumbón & 51 \\
\hline IX & Tintilla & 52 \\
\hline$x$ & Tinto & 52 \\
\hline $\mathrm{XI}$ & Garabatona & 53 \\
\hline XII & Virgiliana & 54 \\
\hline XIII & Beba & 54 \\
\hline XIV & Zurumi & 55 \\
\hline$X V$ & Doradillo-plateado & 56 \\
\hline XVI & Mantúo perruno & 57 \\
\hline XVII & Ximénez-Pedro Ximénez & 58 \\
\hline XVIII & Perruno & 60 \\
\hline XIX & Vigiriego & 61 \\
\hline$x X$ & Melonera & 62 \\
\hline$X X I$ & Ferrar común & 63 \\
\hline XXII & Zucarí & 64 \\
\hline XXIV & Quebrantatinajas & 64 \\
\hline$X X V$ & Santa Paula & 66 \\
\hline XXVI & Ataubí & 67 \\
\hline XXVII & $\begin{array}{l}\text { Uva de Ragol, vulgarmente } \\
\text { llamada Culo de horza }\end{array}$ & 68 \\
\hline XXVIII & Teta de negra & 69 \\
\hline XXIX & Almuñécar & 70 \\
\hline$x X X$ & $\begin{array}{l}\text { Moscatel gordo morado- } \\
\text { Moscatelón encarnado }\end{array}$ & 71 \\
\hline XXXI & Moscatel gordo blanco & 71 \\
\hline XXXII & Jami & 72 \\
\hline XXXIII & Mollar de Granada & 74 \\
\hline XXXIV & Cañocazo-Mollar blanco & 75 \\
\hline$x X X V$ & Uva de rey-Tamorlana & 75 \\
\hline XXXVI & Ciuti & 75 \\
\hline XXXVII & Casta de Ohanez & 76 \\
\hline XXXVIII & Palomino común & 76 \\
\hline
\end{tabular}

Fuente: elaboración propia. 
Figura 2. Ejemplo de buen estado de conservación de uno de los pliegos del herbario de vid de Simón de Rojas Clemente.

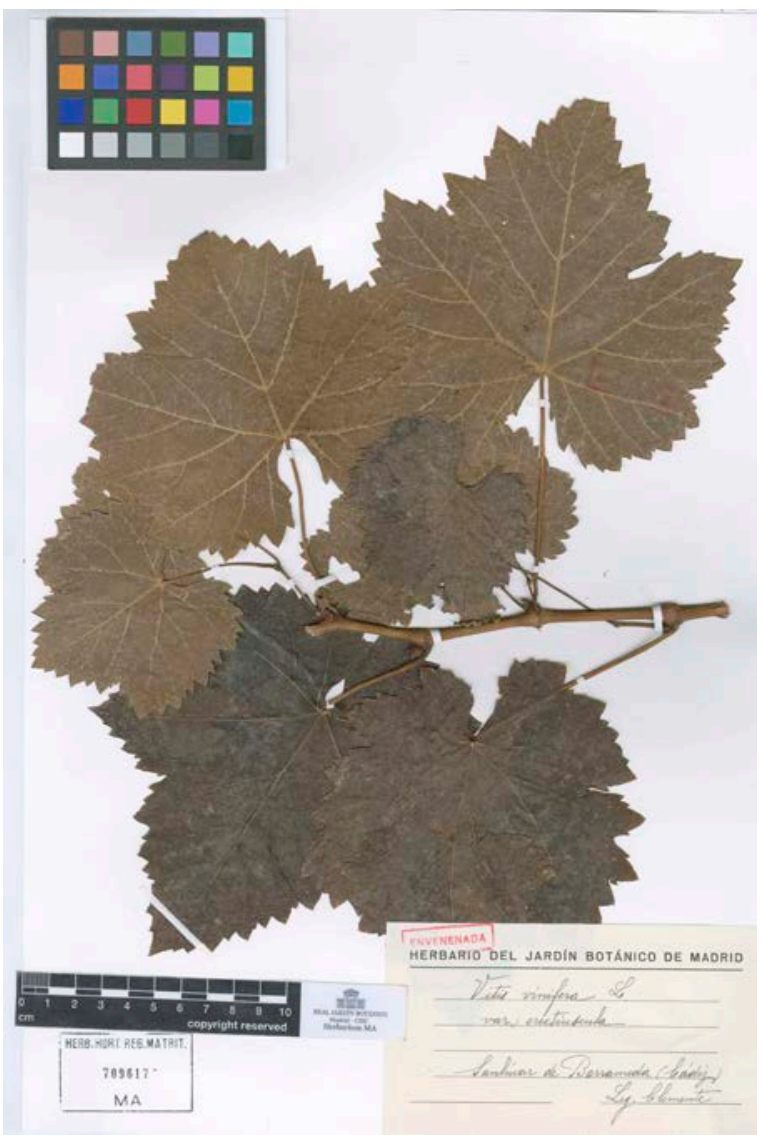

Fuente: Real Jardín Botánico (Madrid).

En la actualidad las colecciones herborizadas conservadas en museos y jardines botánicos están siendo redescubiertas y tratadas como verdaderos "cofres del tesoro" no solo por los botánicos, sino también por especialistas de otras áreas científicas como la biología molecular. Ejemplo de este creciente interés por los ejemplares herborizados es la aparición reciente de una nueva disciplina, la museómica (Zedane et al., 2016), término que no está exento de controversia, y que define la ciencia que estudia el ADN conservado en las numerosas colecciones guardadas en los museos. En las últimas décadas se ha avanzado enormemente en el desarrollo de técnicas que permiten hacer uso del ADN histórico (ancient DNA) y que han convertido las colecciones museísticas y los herbarios en fuentes de material para estudios genéticos y genómicos (Yeates, Zwick y Mikheyvev, 2016). El herbario de Clemente posee un material vegetal con un gran potencial para este tipo de estudios, ya que además de ser la colección de vid herborizada más antigua de la que se tiene conocimiento, posee la particularidad de que sus pliegos fueron la base para su ensayo sobre descripción de variedades, en el que se incluye gran cantidad de información adicional de todo tipo (agronómica, histórica, social ...), que fue recopilada de manos del propio autor en el momento y en los lugares de la prospección. Cada pliego del herbario de Clemente es el producto de la exploración y de la interacción activa del naturalista/ botánico/científico con el medio vitícola existente en un lugar y en un momento concretos. El material del herbario refleja también su experiencia y sirve para estudiar los métodos científicos utilizados en aquella época (Monfils et al., 2017).

A tenor de lo expuesto anteriormente, queda patente el indudable interés museístico de este material, tanto para museos relacionados con la ciencia, como para museos relacionados con el ámbito del enoturismo o la vitivinicultura. Los 186 pliegos del herbario pueden ser fácilmente reproducidos a través de fotografías de alta resolución, para exhibir en diferentes formatos en cualquier tipo de museo. Como se ha citado ya anteriormente, según los datos de los que se dispone, este herbario puede ser considerado el más antiguo del mundo de variedades de vid cultivadas. En él se incluyen variedades actualmente emblemáticas de algunas denominaciones de origen y zonas vitícolas no solo de España, sino también de otras partes del mundo. Además de las numerosas variedades de uvas para vinificación en el herbario hay un número importante de variedades de uvas de mesa e incluso se sospecha que alguna Vitis sylvestris, cuestión esta última que está siendo estudiada desde hace ya varios años por los autores de este trabajo y cuyos resultados serán publicados próximamente.

El herbario de Clemente y la información que el propio autor recopiló durante su estudio de las variedades de vid en Andalucía constituyen una fuente muy interesante de información para entender y poner en valor la herencia vitivinícola de esa zona concreta del sur de España, y por consiguiente de la viticultura europea. Las referencias históricas y la herencia cultural existente en torno a sus variedades pueden suponer un buen reclamo turístico y una gran ventaja a la hora de diferenciarse y de crear estrategias de comercialización en un mundo tan competitivo como el del vino.

Los recorridos realizados por Clemente en la búsqueda de las distintas variedades conservadas en el herbario podrían incluso formar parte hoy en día de las numerosas rutas enoturísticas que han proliferado en los últimos años por la Península Ibérica. Sin embargo, esta ruta tendría la peculiaridad de su valor 
histórico y científico que no tendría ninguna otra ruta del vino en el mundo, ya que ningún experto en ampelografía dejó por escrito los lugares recorridos para la recogida del material vegetal que se conserva en el herbario y al que a la vez hace referencia en un libro.

La promoción de estudios relacionados con el herbario de Clemente tendrá resultados no solo en el plano científico, sino también en el plano turístico y de promoción del patrimonio agrario, así como en el ámbito cultural. En el plano científico se está realizando una colaboración con el grupo del doctor Boursiquot (Instituto Nacional de la Investigación Agronómica de Francia, INRA) para el estudio ampelográfico y molecular del herbario de Clemente, comparándolo con la información y el material vegetal presente en las bases de datos de la Colección de Vid Mundial de Vassal, perteneciente a esta institución. Por otro lado, el trabajo de Clemente y su herbario formó parte importante de la exposición La vid, el vino y el CSIC que se inauguró en el Real Jardín Botánico de Madrid en octubre de 2015, con gran éxito de público y repercusión mediática (Martínez Rodríguez, Carrascosa Santiago y Santiago Blanco, 2016). El herbario y su historia atrajeron la atención de numerosas bodegas de Andalucía (una de ellas incluso patrocinó parte de la exposición) como un modo de diferenciarse y de destacar el valor histórico de sus viñedos que invita al público a conocerlos.

El herbario de Clemente ha llegado a nosotros en perfectas condiciones y constituye una ventana abierta al pasado de la viticultura española e incluso mundial, gracias al momento en el que los ejemplares fueron recogidos, antes de que el viñedo europeo sufriera la mayor crisis de su historia. El herbario de Clemente nos permite realizar comparaciones entre distintos tiempos y estudiar cuestiones como la biodiversidad vitícola existente en la época prefiloxérica o incluso temas relacionados con el tan traído y tan llevado cambio climático.

\section{EL HERBARIO Y LAS VARIEDADES DE VID ESTUDIADAS POR CLEMENTE, MATERIAL VEGETAL BASE PARA LA CREACIÓN DE UNA DISCIPLINA CIENTÍFICA, LA AM- PELOGRAFÍA}

Las variedades incluidas en este herbario fueron las utilizadas por Clemente para desarrollar en 1803 una nueva disciplina científica, la ampelografía, y para poner a punto el método científico de descripción de las variedades de vid que todavía hoy sigue vigente y es utilizado por expertos de todo el mundo.

El término ampelografía, que procede del griego

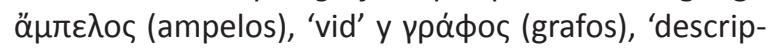

ción', fue utilizado por primera vez por Sachs (1661). Sin embargo, se reconoce al español Simón de Rojas Clemente y Rubio como el padre de esta disciplina científica y quien estableció el término ampelografía para referirse a las descripciones botánicas y agronómicas de las variedades de vid, llegando a afirmar incluso algunos de los más reconocidos autores (Viala y Vermorel, 1910), que lo propuso ignorando que Sachs lo había empleado con anterioridad.

En la forma de clasificar las distintas variedades de vid, la manera de describir sus distintos órganos, las recomendaciones de uso de cada una de ellas e incluso los nombres que les asigna (en latín en algunos casos y nombres vulgares en otros), se refleja perfectamente su pensamiento, la época en que vivió, su formación como botánico, así como la influencia de su maestro Cavanilles y, a través de este, de Linneo.

Comparando las descripciones de Clemente con las realizadas con anterioridad por otros autores, tanto españoles (Abu Zaccaria, siglo XII trad. Banqueri, 1878; Alonso de Herrera, 1513/1818) como de otros países de Europa (Rozier, 1772), se puede decir que se trata de la primera descripción de variedades de vid en la que se utiliza la metodología y la terminología propias de la botánica científica, de la botánica académica. Las descripciones que realiza de los brotes, las flores, hojas y frutos de la vid en general y de cada variedad en particular son exhaustivas y absolutamente precisas. Da información sobre las características y detalles que deben ser observados en cada una de las partes que conforman una planta de vid (sarmientos, pámpanos, brotes, hojas, racimos, bayas, semillas...), así como de las morfologías, colores y distintas variantes que podemos encontrar en cada uno de estos órganos y que nos permiten diferenciar unas variedades de otras. Establece toda una serie de términos para describir y nombrar cada parte de la planta y lo hace de una manera que nunca hasta entonces lo había hecho nadie, describiendo aspectos sobre la planta de vid totalmente inéditos hasta entonces. Sirva como ejemplo de precisión un pequeño párrafo de la descripción que hace de una flor de vinífera, para lo cual emplea cinco páginas del libro: "En la flor de vid deben distinguirse quatro partes principales: el Cáliz (Calix), la Corola (Corolla), los Estambres (Stamina) y el Pistilo (Pistillum); y otras dos menos importantes: el Disco (Discus) y las Glándulas (Glandulae). De estas dos últimas la primera no se había determinado bien hasta ahora; de la segunda no ha hablado nadie que yo sepa...". Sorprende la exactitud y certera descripción que hace de la flor, teniendo en cuenta además que en las viníferas es de un tamaño 
minúsculo y que actualmente las observamos a través de potentes lupas binoculares, inexistentes en aquella época. Algo similar ocurre con los racimos (Uvae, Racemi, Botry, Botriyones), a cuya descripción general dedica otras cinco páginas, o con las uvas o granos de uva (Acini) a los que dedica doce páginas y así sucesivamente. No existe ninguna característica macroscópica de las viníferas o que pueda observarse a través de una lupa de mano sencilla que no aparezca descrita en el libro de Rojas Clemente (1807) con todo lujo de detalles. Hasta tal punto fue válido y científicamente correcto el trabajo de Clemente que todavía hoy el Código de los caracteres descriptivos de las variedades y especies de Vitis de la Organización Internacional de la Vid y el Vino (2009) incluye numerosos parámetros e incluso terminologías propuestas por Clemente que utilizan hoy los ampelógrafos de todo el mundo. Llega incluso Clemente a sugerir el estudio de parámetros para los que en aquella época no existía la tecnología de análisis adecuada pero que actualmente se podrían abordar, tales como las distintas tonalidades de los verdes en las hojas, que podrían ser estudiadas ahora a través de análisis de imágenes: "yo no he visto dos vidueños en que las hojas fuesen exactamente del mismo color y con el mismo grado de intensidad. Si pudiera mi imaginación retener exactamente las impresiones que me hicieron los colores de cada vidueño, y tuviésemos voces con que expresar sus diferencias tan distintamente como yo las sentí, bastaría este carácter solo para distinguir todas las variedades que he descrito, y tal vez todas las existentes". En el tratado de Rojas Clemente (1807) se encuentran incluso algunos caracteres ampelográficos raros de algunas variedades concretas a los que solo él hace referencia y describe con todo detalle.

Pero el ensayo de Clemente además no se reduce a la descripción de las numerosísimas variedades de vid existentes y a la puesta a punto de un método científico para ello, sino que pone sobre la mesa temas tan importantes, tan de actualidad y sobre los que quedan muchas cuestiones por estudiar, como es la variación no solo dentro de una especie (variedades), sino también dentro de una variedad (clones), dando algunas claves de las reglas que la rigen.

\section{LOS NOMBRES ASIGNADOS POR CLEMENTE A LAS VARIEDADES DE VID ESTUDIADAS Y SU CORRESPON- DENCIA CON LOS NOMBRES ACTUALES}

Al analizar la obra de Clemente Ensayo sobre las variedades de vid común que vegetan en Andalucía (Rojas Clemente y Rubio, 1807), tanto en su primera edición como en la posterior edición ilustrada (1879), se puede pensar que no es necesario hacer un estudio del herbario para conocer la correspondencia con las variedades actuales y que simplemente con ver los nombres de las que aparecen en el libro y las ilustraciones que acompañan en la edición de 1879 a algunas de ellas ya sería posible identificarlas. Sin embargo, esto no es así y no es ni mucho menos fácil conocer la correspondencia de muchas de las variedades descritas por Clemente con las actuales. Desde tiempos inmemoriales las variedades de vid tienen nombres vulgares, que se han ido transmitiendo de padres a hijos, generación tras generación, y que han permitido a viticultores de todas las épocas reconocerlas. En unos casos esos nombres son conocidos en el ámbito local, nacional o internacional porque la variedad, se haya extendido poco o mucho, ha mantenido siempre su nombre (Cabernet Sauvignon, Tempranillo...). En otros casos, a medida que se iban extendiendo por diversas zonas, iban adquiriendo nombres locales diferentes en cada uno de los lugares a los que llegaban. Un ejemplo de esto sería la variedad andaluza Palomino Fino, que en su "recorrido" por diferentes regiones de España acabó adquiriendo nombres locales como Jerez, Blanca Extra, o Listán Blanco, entre otros (Cabello et al., 2011; Martínez et al., 2018).

En el caso de las variedades descritas por Clemente la cuestión se complica aún más, ya que él, salvo para un pequeño número de ellas que se encuentran identificadas, tanto en el libro como en el herbario, con los nombres tradicionales que han perdurado hasta la actualidad (Tempranillo, Tintilla,...), al resto les fue asignando nombres en honor a diferentes sabios de la antigüedad (Pliniana en honor a Plinio; Virgiliana en honor a Virgilio; Catonis en honor a Catón, etc.), o recordando a sus maestros, mentores y botánicos admirados por él (de Boutelou, en honor a Boutelou, Rozierii en honor a Rozier; Langleya, en honor a Langley, etc.) o a alguna característica diferenciadora de la variedad (Albicans por el color blanquecino; Acidula por su elevada acidez, Fertilis por su elevada fertilidad). Todo ello hace imposible relacionar estas descripciones con las variedades actualmente conocidas, sin un minucioso estudio ampelográfico del herbario complementado con un análisis empleando marcadores moleculares. Aunque esta manera de nombrar las variedades pueda parecer extraña, no lo es tanto si tenemos en cuenta la formación de Clemente como botánico y la época en que vivió, en la que la botánica era una de las ciencias más importantes, respetadas y admiradas, y los botánicos eran considerados la élite científica. Quizás le parecía poco científico asignarles los nombres vulgares con los que eran conocidas, 
puesto que la lengua de la ciencia en aquella época era el latín, y pretendía con la atribución de nombres en latín, o dedicados a grandes sabios, introducir la vid cultivada en la élite científica de la época, o al revés, acercar la ciencia a una especie tan importante para la agricultura, la economía y la cultura. Por otro lado, los siglos XVIII y XIX estuvieron marcados por las grandes expediciones botánicas al nuevo mundo, por el nacimiento de la taxonomía botánica de la mano de Linneo con su obra Species plantarum, ciencia que llegó a España a través de Cavanilles (maestro de Clemente) y por la realización de numerosos estudios en toda Europa sobre sistemática y sobre la flora existente en cada país. En esta época se describieron por primera vez, siguiendo las pautas de la taxonomía y la sistemática, numerosas especies vegetales desconoci- das hasta entonces, a las que los botánicos asignaban nombres en latín relacionados unas veces con alguna característica típica de la planta en cuestión o con su lugar de procedencia o con el botánico que la describía. Analizado desde este punto de vista, el hecho de que Clemente asignase nombres cultos elegidos por él a las distintas variedades que describía era lo normal en la época y lo que todos esperaban que hiciese.

\section{AGRADECIMIENTOS}

Parte del estudio del herbario de vides de Clemente ha sido financiado por Bodegas Grupo Estévez. Los autores agradecen también la colaboración del personal del Real Jardín Botánico (CSIC), en especial de Esther García Guillén. El resumen en inglés ha sido realizado por Adrian Burton (www.physicalevidence.es).

\section{BIBLIOGRAFÍA}

Abu Zacaria (1878). Libro de agricultura. Arreglo hecho en vista de la traducción castellana de D. José Banqueri por D. Claudio Boutelou, precedido de una introducción escrita por D. Esteban Boutelou, y seguido del "Catecismo de Agricultura" por Victor van den Broeck; y de "Los abonos químicos" [...] por $M$. Georges Ville. Sevilla: Administración de la Biblioteca científico-literaria, Madrid: Librería de D. Victoriano Suárez.

Alonso de Herrera, G. (1513/1818). Agricultura general. Corregida según el texto original de la primera edición publicada en 1513 por el mismo autor y adicionada por la Real Sociedad Económica Matritense. Madrid: Imprenta Real.

Andrés, M. T. de, Benito, A., Pérez-Rivera, G., Ocete, R., López, M. A., Gaforio, L. y Arroyo-García, R. (2012). Genetic diversity of wild grapevine populations in Spain and their genetic relationships with cultivated grapevines. Molecular Ecology, 21 (4), pp. 800-816. https://doi. org/10.1111/j.1365-294X.2011.05395.x

Cabello, F., Rodríguez-Torres, I., MuñozOrganero, G., Rubio, C., Benito, A., García-Beneytez, S. (2003). La colección de variedades de vid de "El Encín". Un recorrido por la historia de la ampelografía. Madrid: Instituto Madrileño de Investigación Agraria y Alimentaria. Disponible en http://www.madrid.org/ bvirtual/BVCM005577.pdf

Cabello, F., Ortiz, J. M., Muñoz, G., Rodríguez, I., Benito, A., Rubio, C., García, S. y Sáiz, R. (2011). Variedades de vid en España. Madrid: Editorial Agrícola Española.
Dosil Mancilla, F. J. (2007). Los albores de la botánica marina española (1814-1939). Madrid: Consejo Superior de Investigaciones Científicas.

Escribano Martín, F. (2005). El peregrino Ali-Bey, un "príncipe abasí» español del siglo XIX. Arbor CLXXX, 711-712, pp. 757-771. https://doi.org/10.3989/ arbor.2005.i711/712.470

Fernández Perez, J. y Gomis Blanco, A. (1990). La Ceres española y la Ceres europea, dos proyectos agrobotánicos de Mariano La Gasca y Simón de Rojas Clemente. Llull. Revista de la Sociedad Española de Historia de las Ciencias y de las Técnicas, 13 (25), pp. 379-402.

Föex, G. (1891). Cours complet de viticulture ( $3^{\mathrm{ème}}$ ed.). Paris: Georges Masson, Libraire-Éditeur.

Johnson, H. (1990). Une histoire mondiale du vin. De l'Antiquité à nos jours. Paris: Hachette.

Martín Polo, F. (2016). Simón de Rojas Clemente. Valencia: Publicaciones Universidad de Valencia.

Martínez, M. C., Boso, S., Gago, P., MuñozOrganero, G., Andrés, M. T. de, Gaforio, L., Cabello, F. y Santiago, J. L. (2018). Value of two Spanish live grapevine collections in the resolution of synonyms, homonyms and naming errors. Australian Journal of Grape and Wine Research, 24, pp. 430-438. https://doi. org/10.1111/ajgw.12348

Martínez Rodríguez, M. C., Carrascosa Santiago, A. V. y Santiago Blanco, J. L. (eds.) (2016). La vid, el vino y el CSIC: dos siglos de investigación = Vines, wines and the CSIC: two centuries of research. Madrid: Consejo Superior de Investigaciones Científicas.

Monfils, A. K., Powers, K. E., Marshall, C. J., Martine, C. T., Smith, J. F. y Prather, L. A. (2017). Natural history collections: teaching about biodiversity across time, space, and digital platforms. Southeastern Naturalist, 16 (Special Issue 10), pp. 47-57. https://doi. org/10.1656/058.016.0sp1008

Ocete Rubio, R., Cantos Barragán, M., López Martínez, M. A., Gallardo Cano, A., Pérez Izquierdo, M. A., Troncoso de Arce, A., Lara Benítez, M., Failla, O., Ferragut Pérez, F. J. y Liñán Benjumea, J. (2007). Caracterización y conservación del recurso fitogenético. Vid silvestre en Andalucía. Granada: Fundación Andaluza del Alcornoque y el Corcho.

Rojas Clemente y Rubio, S. de (1807). Ensayo sobre las variedades de la vid común que vegetan en Andalucía, con un índice etimológico y tres listas de plantas en que se caracterizan varias especies nuevas. Madrid: en la Imprenta de Villalpando.

Rojas Clemente y Rubio, S. de (1879). Ensayo sobre las variedades de la vid común que vegetan en Andalucía. Edición ilustrada hecha de real orden, en honra del autor y en memoria de la primera exposición vinícola nacional celebrada en España, siendo ministro de Fomento el excelentísimo señor Conde de Toreno y director general de Agricultura, Industria y Comercio el excelentísimo señor don José de Cárdenas. Madrid: Imprenta Estereotipia Perojo. 
Roy-Chevrier, J. (1900). Ampélographie rétrospective. Histoire de l'Ampélographie. Biographies et Textes annotés d'auteurs antérieurs à Bosc. Bibliographie viticole de Bosc à Odart. Montpellier: Coulet et fils, éditeurs, Paris: Masson et $\mathrm{C}^{\mathrm{i}}$ éditeurs.

Rozier, F. (1772). Mémoire sur la meilleure manière de faire et de gouverner les vins de Provence, soit pour l'usage, soit pour leur faire passer les mers. Paris: Le Jay.

Sachs, J. P. (1661). Ampelographia. Leipzig.

Viala, P. y Vermorel, V. (dirs.) (1910). Ampélographie. Paris: Masson et $C^{\text {ie }}$ éditeurs.
Yeates, D. K., Zwick, A. y Mikheyev, A. S. (2016). Museums are biobanks: unlocking the genetic potential of the three billion specimens in the world's biological collections. Current Opinion in Insect Science, 18, pp. 83-88. https://doi. org/10.1016/j.cois.2016.09.009

Zedane, L., Hong-Wa, C., Murienne, J., Jeziorski, C. Baldwin, B. G. y Besnard, G. (2016). Museomics illuminate the history of an extinct, paleoendemic plant lineage (Hesperelaea, Oleaceae) known from an 1875 collection from Guadalupe Island, Mexico. Biological Journal of Linnean Society, 117 (1), pp. 44-57. https://doi.org/10.1111/bij.12509

\section{Otros recursos}

Lista de descriptores OIV para variedades de vid y especies de Vitis (2.a edición). [En línea]. Disponible en: http://www. oiv.int/es/normas-y-documentos-tecnicos/descripcion-de-variedades/listade-los-descriptores-oiv-para-las-variedades-y-especies-de-vitis-2\%C2\%AAedicion 